\title{
DIVERSIDADE DE GÉNERO NA INFÂNCIA E EDUCAÇÃO: CONTRIBUTOS PARA UMA ESCOLA SENSÍVEL AO (TRANS)GÉNERO
}

\section{Resumo}

Este artigo incide sobre a diversidade de género na infância e juventude, pretendendo mapear as dificuldades e desvantagens que se colocam a crianças e jovens com identidades e expressões de género diversas no decurso do seu percurso escolar. Para tal, recorreu-se a entrevistas de carácter biográfico a mais de três dezenas de pessoas trans(género) adultas, que relataram as suas experiências de infância e juventude. Corroborando o encontrado em outros estudos, os resultados apontam para um panorama de estranheza, desamparo e mesmo violência em ambiente escolar, que evidenciam a necessidade de implementar medidas especificamente direcionadas a esta problemática, mas também a sua incorporação nos instrumentos de combate ao sexismo e estereótipos de género.

Palavras-chave: Diversidade de género na infância, transgénero, educação, políticas educativas.

\section{Abstract school \\ Gender diversity in childhood and education: Towards a (trans)gender-sensitive}

This article focuses on the gender diversity in childhood and youth, aiming to map the difficulties and disadvantages faced by children and young people with diverse identities and gender expressions in the course of their school career. More than three dozen of trans(gender) adults were interviewed, describing their experiences as children and young people. Corroborating what has been found in other studies, the results point out to a panorama of strangeness, helplessness and even violence in school, which stress the need to implement measures specifically aimed at this problem, as well as its incorporation into tools and initiatives to fight sexism and gender stereotypes. policies.

Keywords: Gender diversity in childhood, transgender, education, educational

\section{Resumen}

Diversidad de género en la infancia y educación: Contribuciones a una escuela sensible al (trans)género

Este trabajo se refiere a la diversidad de género en la infancia y juventud, pretendiendo mapear las dificultades y desventajas que se plantean a niños, niñas y jóvenes con

Centro de Investigação e Estudos de Sociologia (CIES), Instituto Universitário de Lisboa (ISCTE-IUL), Portugal

Endereço eletrónico: sandra.saleiro@iscte.pt

Endereço postal: Centro de Investigação e Estudos de Sociologia (CIES), Edifício ISCTE. Avenida das Forças Armadas, 1649-026 Lisboa, Portugal. 
identidades y expresiones de género diversas en el curso de su recorrido escolar. Para ello, se recurrió a entrevistas de carácter biográfico a más de tres decenas de personas trans(género) adultas, que relataron sus experiencias de infancia y juventud. Tal como otros estudios han demostrado, los resultados apuntan a un panorama de extrañeza, desamparo e incluso violencia en ambiente escolar, que evidencian la necesidad de implementar medidas específicamente dirigidas a esta problemática, pero también su incorporación en los instrumentos de combate al sexismo y los estereotipos de género.

Palabras clave: Diversidad de género en la infancia, transgénero, educación, políticas educativas.

\section{Introdução}

Este artigo centra-se numa dimensão das desigualdades de género na educação que nem sempre é considerada, mesmo nas abordagens sensíveis ao género, seja ao nível da produção de conhecimento científico, seja na conceção e implementação de políticas, instrumentos e iniciativas de promoção da igualdade de género no campo educativo. Trata-se das desigualdades entre as crianças e jovens que se apresentam diversas em termos de género, que recaem sob a ampla cobertura do transgénero, e as que se identificam e se expressam de modos expectáveis face ao sexo que lhes foi atribuído à nascença. As crianças trans ou diversas em termos de género só muito recentemente emergiram como uma nova categoria social (Meadow 2011), tendo-se inaugurado a sua contemplação nas orientações internacionais para a educação. Estas encontram-se já substanciadas em alguns países, estando em fase de discussão noutros, como é o caso de Portugal. Os estudos que abordam especificamente, ou incluem, a problemática da diversidade de género na escola são ainda escassos (Cabezas, Ortega, e Galán 2013), mais ainda se só se tiver em conta a realidade portuguesa.

Em Portugal, tem vindo a constituir-se um património de estudos sobre as questões da identidade de (trans)género nas ciências sociais que, proveniente de áreas disciplinares diferentes e com distintos posicionamentos, tem contribuído para a compreensão do fenómeno (p. ex., Saleiro 2013; Pinto 2015; Rodrigues, 2016). Não existem ainda, porém, estudos que se debrucem especificamente sobre a infância ou que tomem as crianças e jovens trans como protagonistas. São, por isso, necessários investimentos no sentido do mapeamento de necessidades, sugestão de medidas e identificação de boas práticas na promoção da inclusão da diversidade de género no sistema educativo.

Neste artigo pretende-se contribuir para o preenchimento daquele vazio, tendo como objetivo identificar os problemas que se colocam às crianças e jovens diversas em termos de género no sistema educativo em Portugal, bem como refletir sobre as consequências da sua invisibilização (Cabrera e Cabezas 2013), não reconhecimento e ininteligibilidade (Butler 2004) no espaço escolar. Para isso, revisitam-se os testemunhos de mais de três dezenas de pessoas de diversas identidades 
e expressões de (trans)género, maiores de idade, obtidos no decurso de um projeto de investigação ${ }^{1}$ que, não tendo a infância como período delimitado de investigação, ou a educação como única dimensão central, produziu informação abundante sobre as experiências escolares das pessoas trans. Embora de modo diferido, já mediado pela memória, o acesso à «experiência vivida contextualizada» (Monro 2010, 248) de pessoas trans adultas, no que respeita à escola, com recurso a entrevistas aprofundadas de carácter biográfico, é uma das modalidades possíveis de acesso às experiências de crianças trans (Riley et al. 2013) na escola, atendendo aos desafios, nomeadamente éticos, que se colocam à auscultação direta desta população (Platero 2014, 151).

$\mathrm{O}$ artigo divide-se em três partes. Começa-se por dar conta do processo de visibilidade e reconhecimento da diversidade de género na infância, introduzindo os principais conceitos para o seu entendimento. Avança-se depois na sinalização de alguns progressos que se têm verificado no seu reconhecimento ao nível das políticas públicas, com destaque para a educação. Na terceira parte, convocam-se experiências de pessoas trans no decurso do seu percurso escolar, que permitem retirar ilações para o combate às desvantagens que se colocam a estas crianças e jovens, e avançar com algumas medidas recomendáveis.

\section{A emergência das crianças trans ou diversas em termos de género como uma nova categoria social}

As pessoas que transgridem a relação tida como natural e fixa entre o sexo que lhes foi atribuído à nascença e a identidade e a expressão de género que socialmente lhes corresponde, que recaem sob a alçada do «transgénero», só recentemente têm vindo a ser objeto de atenção fora de uma perspetiva patologizante, tanto a nível social, quanto ao nível das ciências sociais. Para tal, muito contribuiu a ação dos movimentos sociais e dos/as próprios/as académicos/as trans. Sobretudo a partir dos anos 1990, começa a constituir-se um corpo de trabalho na área dos «estudos transgénero» e a consolidar-se a categoria institucional de «identidade de género» para abarcar este fenómeno. Tem-se vindo desde essa altura a assistir a uma mudança de paradigma na interpretação deste fenómeno, desde a sua localização exclusiva no âmbito da medicina e dos catálogos de doenças mentais para a esfera dos direitos humanos, plasmados nos Princípios de Yogyakarta para Aplicação das Leis dos Direitos Humanos em Relação à Orientação Sexual e à Identidade de Género (Yogyakarta Principles 2007).

Não havendo uma definição única de «transgénero», ou apenas «trans», termo que tem vindo a ser crescentemente utilizado para abranger a maior diver-

Projeto «Transexualidade e Transgénero: Identidades e Expressões de Género», desenvolvido no CIES-IUL (2007-2010) e financiado pela FCT - Fundação para a Ciência e a Tecnologia. Parte substancial dos resultados encontra-se em Sandra Saleiro (2013). 
sidade de identidades e expressões de género fora das socialmente expectáveis, pode ser definido como abarcando as pessoas que se identificam com um género que não (exclusivamente) aquele que lhe foi atribuído à nascença. Isto pode significar alguém reconhecido como do género masculino à nascença, mas que se identifica com o feminino ou vice-versa, ou que se identifica com as duas ou com nenhuma das categorias binárias de género comummente aceites (Sanger 2010, 272). Já «cisgénero», ou apenas «cis», abarca as pessoas para as quais coincidem o sexo atribuído à nascença e a identificação de género (Stryker 2008; Sanger 2010). As pessoas trans, enquanto detentoras de identidades de género socialmente minoritárias, e transgredindo um dos principais pilares em que assentam e se estruturam as sociedades - o da existência de dois sexos/géneros únicos, fixos e dicotómicos -, são dos grupos mais discriminados da população, como revelam dados apurados a nível europeu (Comissão Europeia 2015) e nacional (Costa et al. 2010, 109-110). Coexistindo com o privilégio da masculinidade, há ainda que reconhecer o «cisprivilégio» (Enke 2012); e ao sexismo que continua a caracterizar as sociedades contemporâneas, deve juntar-se o cisgenderismo como traço das desigualdades de género. O cisgenderismo é a ideologia que invalida ou patologiza as autoatribuições de género que contrastam com as externamente atribuídas (Ansara e Hegarty 2012).

Desde os anos 1960 que as identidades e expressões de género não normativas das crianças têm sido objeto de atenção e perspetivadas como uma patologia que necessita de cura (Bryant 2006; Pyne 2014). A «perturbação de identidade de género na infância» foi introduzida formalmente, em 1980, na terceira revisão do DSM - Manual de Diagnóstico e Estatística das Perturbações Mentais da Associação Americana de Psiquiatria, sendo advogadas terapias reparadoras, no sentido de alinhar estas crianças com as normas sociais de género. No entanto, e embora mais tardiamente do que para a população adulta, tem-se vindo a assistir a uma mudança de paradigma também para a infância. Da prática clínica começam a surgir outras leituras que recolocam a variedade de expressões de género na infância como parte da diversidade humana (Lev 2004; Ehrensaft 2012; Menvielle 2012).

A «diversidade de género» (Monro 2010) tem vindo a impor-se como termo descritivo deste fenómeno, numa tentativa de posicionar as identidades e expressões de género minoritárias como parte das possibilidades da humanidade de ser e parecer em termos de género, contribuindo para diluir fronteiras rígidas entre o cis e o transgénero. A sua utilização com referência a crianças e jovens é ainda mais pertinente porque evita a atribuição de categorias identitárias de género (como a de transexual), deixando espaço para a autodeterminação de género. Os estudos realizados na infância (Pyne 2014) têm revelado que, tal como na população adulta (Ekins e King 2006; Saleiro 2013), existem modos distintos de sentir e expressar a diversidade de género. Estes podem envolver desde reivindicações persistentes de pertença identitária ao «outro» sexo (no que se diz que se é, na escolha de um novo nome e género gramatical), até ao desejo de apropriação do universo reservado ao «outro» género (na escolha da roupa e acessórios, brinquedos e brincadeiras, etc.), 
com maior ou menor frequência e intensidade, não reivindicando necessariamente uma outra pertença de género.

No mesmo sentido, e também porque a linguagem não descreve apenas a realidade mas produz realidade, um dos mais significativos indícios da mudança de paradigma são as expressões que começam a emergir para referenciar estas crianças, concorrendo com as que vigoram no discurso médico tradicional, assentes na patologia («perturbação de identidade de género na infância»), e que assumem um sentido positivo e afirmativo: «crianças independentes em termos de género» (Pyne 2014), «crianças variantes em termos de género» (Rahilly 2015), «crianças não conformes em termos de género» (Platero 2014). Este novo modelo propõe assim uma deslocação no foco da intervenção, desde um problema ou mesmo patologia individual da criança até ao trabalho que é necessário fazer para a sua aceitação na comunidade (Pyne 2014).

A diversidade de género na infância e juventude vai-se tornando cada vez mais visível e reconhecida e interpelando as políticas públicas, incluindo as educativas, à medida que as mães e os pais destas crianças e jovens vão ficando conscientes deste fenómeno e com maior disponibilidade para apoiar os seus filhos e filhas na sua vivência de género, e se vão encontrando (para o que muito contribui a Internet) e criando formas de mobilização e reivindicação coletiva, de que são exemplo as associações de mães e pais de crianças trans ou diversas em termos de género. Também em Portugal, a manifestação desta realidade levou a que a AMPLOS (Associação de Mães e Pais pela Liberdade de Orientação Sexual e Identidade de Género) criasse a secção AMPLOS Infância. Aliás, são as mães e os pais destas crianças, ao apoiarem-nas na sua livre expressão de género, que possibilitam a própria emergência da categoria de crianças trans ou diversas em termos de género (Meadow 2011). Não porque não tivessem existido antes, como mostram as narrativas das pessoas trans adultas, mas porque está neste momento a constituir-se a primeira geração de crianças a quem é permitido viver de acordo com o seu (trans)género em todas as dimensões da sua vida e assim serem reconhecidas (Meadow 2011; Olson et al. 2016).

Mas o apoio da família terá que ser acompanhado noutras esferas da vida. No redirecionamento da intervenção, as escolas constituem um dos atores estratégicos (Pyne 2014), tendo os estudos já realizados salientado a necessidade de as escolas criarem um ambiente mais acolhedor através de políticas e currículos aptos a apoiar crianças com diversidade de expressões de género (Meyer 2009; Pichardo 2009; Platero 2010; Cabezas, Ortega, e Galán 2013; Gavilán, 2016).

\section{Diversidade de género na infância nas políticas educativas}

Até bem recentemente, a legislação existente nos diversos países, designadamente as chamadas «leis de identidade de género», assumiam que a identificação 
de género era uma característica apenas das pessoas adultas, criando um ambiente de ignorância e de risco para estas crianças e suas famílias (Platero 2014, 162). Esta ausência de atenção à infância tem vindo a alterar-se, com a regulamentação da mudança de nome e menção ao sexo nos documentos de identificação para crianças nas legislações da Argentina $\left(2012^{2}\right)$, Malta $\left(2015^{3}\right)$ e Noruega (2016 $)$. Em Portugal, a lei em vigor (lei 7/2011, de 15 de março) é aplicável apenas a partir da maioridade. No entanto, este é um dos aspetos em debate para o novo quadro jurídico atualmente em discussão, sendo as questões da infância, em moldes e com soluções diferentes, abordadas nas propostas apresentadas pelo BE, ${ }^{5} \mathrm{PAN}^{6} \mathrm{e}$ Governo. $^{7}$

No contexto europeu, a Recomendação CM/REC(2010)5 do Comité de Ministros do Conselho da Europa elenca um conjunto de medidas de combate à discriminação com base na orientação sexual e na identidade de género, no sentido de os Estados-membros adotarem as medidas nela visadas nas respetivas legislações. A educação é uma das áreas contempladas no sentido da «salvaguarda do direito das crianças e jovens à educação num ambiente seguro, livre de violência, bullying, exclusão social ou outras formas de discriminação e tratamento degradante associados à orientação sexual ou à identidade de género» (secção VI) (Conselho da Europa 2010, 5). Recomenda-se a inclusão de informação sobre identidade de género nos currículos e materiais educativos, assim como o fornecimento da informação, a proteção e o apoio que permitam às crianças viver de acordo com a sua identidade de género. Prevê-se ainda o desenho e implementação de medidas de formação para docentes e auxiliares (Conselho da Europa 2010). O Comissário para os Direitos Humanos do Conselho da Europa retoma e atualiza, em 2014, essas recomendações aos Estados-membros, reforçando o direito à educação sexual inclusiva da orientação sexual e da identidade de género para todas as crianças e jovens (Conselho da Europa 2014).

Em termos de políticas estatais nacionais, Malta foi pioneira na inclusão das questões dos/as estudantes trans e variantes em termos de género (e também intersexo) nas escolas, no seu Quadro Estratégico para a Educação 2014-2024. Os objetivos desta política educativa passam por adotar um ambiente escolar inclusivo, seguro e livre de assédio e discriminação para todos os membros da comunidade escolar, e promover a aprendizagem da diversidade humana, contribuindo, desse modo, para a consciência, a aceitação e o respeito social das pessoas trans (Ministry for Education and Employment 2015).

Ley 26.743 «Establécese el derecho a la identidad de género de las personas» de 23 de Maio de 2012.

$3 \quad$ Act N ${ }^{\circ}$ XI de 2015, «Gender Identity, Gender Expression and Sex Characteristics Act, 2015».

4 Prop 74 L (2015-2016), «The legal Gender Amendment Act».

5 Projeto de Lei n ${ }^{\circ}$ 242/XIII/1. ${ }^{a}$, «Reconhece o direito à autodeterminação de género».

6 Projeto-Lei n. ${ }^{\circ}$ 317/XIII/2, «Assegura o direito à autodeterminação de género».

$7 \quad$ Proposta de Lei 75/XIII. 
Em Espanha, um número crescente de províncias tem em vigor leis integrais dirigidas especificamente, ou abrangendo, as questões da identidade e expressão de género, que incluem medidas no âmbito da educação (casos da Andaluzia, desde 2014; Extremadura, 2015; Madrid, 2016; Múrcia, 2016; Valência, 2017²). Em 2015, a Junta da Andaluzia elaborou ainda um «Protocolo de atuação sobre Identidade de Género no Sistema Educativo Andaluz», que detalha medidas e procedimentos para concretizar o estabelecido na lei integral. Entre as muitas medidas consigna o direito e o respeito pela imagem física, indumentária e o acesso e uso das instalações do estabelecimento escolar conforme o género eleito; o direito a utilizar livremente o nome escolhido, que será refletido na documentação administrativa da escola, nas listas de alunos/as, nas qualificações académicas, etc. (Junta de Andalucia 2015).

Em Portugal, desde 2012 que o Estatuto do Aluno (Lei n. . 51/2012) inclui a «identidade de género» como categoria de não discriminação (art. ${ }^{0}$ 7, 1 a), mas até ao presente não foram implementadas medidas específicas no sentido de concretizar esse princípio, encontrando-se agora em discussão. As propostas de lei de identidade de género do BE e do governo contemplam já o compromisso do Estado com medidas para o setor da educação.

\section{Experiências vividas de diversidade de género na escola}

Para a reconstituição das experiências de diversidade de género na escola recorreu-se a entrevistas em profundidade realizadas a 37 pessoas de diversas identidades e expressões de (trans)género maiores de idade, ${ }^{9}$ tendo-se privilegiado, para este artigo, as mais novas. As entrevistas foram submetidas a uma análise de conteúdo qualitativa (Maroy 1997), visando a organização temática do discurso que permitisse aceder a um panorama geral e comparativo. Tratandose de entrevistas de carácter biográfico, que não se centraram exclusivamente na dimensão escolar, os relatos das experiências escolares assumiram um lugar preponderante nas narrativas relativas à infância, embora pudessem ser retomadas ao longo da narração.

\section{$A$ «estranheza» da diversidade de género}

A auscultação de pessoas trans adultas, mesmo aquelas que não foram reconhecidas como tal na infância, revela a consciência da sua situação de (trans)género desde muito cedo. Algumas fazendo precisamente coincidir essa consciência com a entrada para o sistema educativo, onde se confrontam mais sistematicamente

\footnotetext{
Podem ser consultadas em https://www.boe.es.

Para maior detalhe sobre as opções metodológicas veja-se Sandra Saleiro (2013, 105-130).
} 
com a divisão das crianças entre meninos e meninas. Aliás, podem tomar-se as crianças trans como fonte privilegiada de deteção do modelo de segregação sexual que persiste no sistema de ensino, uma vez que, mais do que outras, o sentem e dele dramaticamente se ressentem.

Eu costumo dizer que, desde que me lembro de mim próprio como pessoa, as minhas primeiras recordações já têm esse mal-estar presente. Que eu creio que coincidiu com a entrada no jardim-de-infância, onde estou num local desconhecido, cheio de crianças e há um sistema educativo que várias vezes impõe a separação dos sexos. Eu aí comecei a perceber que me estavam a colocar numa posição, a quererem que eu tivesse um papel social diferente daquele com o qual eu me identificava mais. Portanto, eu queria estar no grupo dos meninos, quer fosse para a fila para a casa de banho, ou para sair para brincar no recreio, e constantemente estavam-me a pôr no local das meninas. (José, ${ }^{10} 28$ anos)

O testemunho de José ilustra a violência da segregação espacial por sexos na escola (Cabezas, Ortega e Galán 2013). Tal como os estudos sobre género (e não necessariamente sobre transgénero) na educação têm salientado (Alvarez e Vieira 2014), é necessário atuar transversalmente para transformar os espaços e as estruturas escolares numa direção mais igualitária e menos segregadora.

É também recorrente nas narrativas das pessoas trans a perceção de que eram notadas e estranhadas por não corresponderem às expectativas de género, algumas logo no jardim-de-infância, como aconteceu com José, e ainda antes de conseguirem sequer localizar e racionalizar a origem dessa estranheza e consequente reprovação e repressão. A não conformidade com as expectativas é encarada pelos/ as protagonistas escolares, onde se destacam os/as professores/as, como um «problema» e assim é comunicado à família.

Assim, para além da associação - ilegítima, como demonstram as crianças e jovens trans mas também outras - automática e naturalizada que se faz na escola entre corpos, pertenças e preferências, uma segunda questão que urge combater é a ideia de que os desvios ao modelo de género dominante constituem um «problema».

Na primária, a minha mãe foi chamada várias vezes pela minha professora primária, que achava que eu era uma criança um bocado estranha porque não me adaptava com os rapazes. Porque o que eu queria fazer era saltar à corda e jogar à macaca e achava os putos um bando de parvos, que andavam a correr atrás de uma bola e a andar à porrada e aquilo não tinha nada a ver comigo. [...] e aquilo para mim era um pânico porque já sabia que a minha mãe me ia bater. Depois, a minha mãe repreendia-me, batia-me, que eu tinha era que brincar com os meninos e não tinha nada que brincar

10 Os nomes utilizados são pseudónimos que as pessoas entrevistadas escolheram para identificação na pesquisa. 
com as meninas, depois era o meu pai, era tudo contra mim. Isto logo a partir dos seis anos. (Vanessa, 36 anos)

Contrariar a comunicação da diferença como «estranheza» é tanto mais importante quanto a postura de profissionais, onde se incluem os/as educadores/ as, enquanto fonte de informação, tem um claro impacto no modo como a família encara a expressão de género da sua criança (Platero 2014). Será pois necessário formar docentes, bem como auxiliares das escolas, em igualdade e diversidade de género, no sentido de os/as dotar de ferramentas para lidar adequadamente com a variedade de expressões de género de crianças e jovens.

\section{Vigilância da masculinidade}

Tal como os estudos sobre transgénero a nível internacional e nacional (p. ex., Stryker 2008; Saleiro 2013) têm revelado, embora as transgressões de género sejam sempre notadas e tenham consequências, a expressão da feminilidade por parte de pessoas percebidas como rapazes/homens é mais severamente penalizada logo desde a infância. Há uma atenta «vigilância» da masculinidade, da sua expressão imprópria ou desadequada, tanto por parte das pessoas adultas como dos pares.

E o que é engraçado é que as meninas [na escola primária] deixavam-me entrar perfeitamente no grupo delas e aceitavam, sem problemas. Depois, eles batiam-me porque eu estava a brincar com elas. Quando eu fui para o ciclo foi muito pior, tive esperas, tive uma tentativa de violação por um grupo dentro da escola. (Vanessa, 36 anos)

A expressão da masculinidade aceitável permanece resistente à inclusão de dimensões socialmente associadas à feminilidade. Já a expressão de dimensões socialmente associadas à masculinidade por parte de raparigas, ou de crianças percebidas enquanto raparigas, não se revela tão problemática na medida em que o masculino é o referente universal e a masculinidade é mais valorizada socialmente e por isso pode, até certa medida, e pelo menos até certa idade (Devor 1989), estender-se às raparigas e às mulheres. Daí que, sobretudo até à adolescência, onde são lidos como «maria-rapaz», os rapazes trans não se ressintam tanto quanto as raparigas trans da repressão da sua expressão de género. Esta desigualdade demonstra, como os estudos de género têm destacado, a necessidade de trabalhar, também na escola, a valorização das dimensões e traços associados ao feminino (Alvarez e Vieira 2014, 10), não tendo que permanecer confinados a quem é reconhecido como rapariga/mulher. Mas as experiências trans demonstram ainda a necessidade de trabalhar na descolagem entre corpos e identidades de género, no sentido de que as dimensões socialmente associadas à masculinidade e à feminilidade podem ser expressadas e incorporadas, em diversas combinações, independentemente do sexo com que se nasce. 


\section{Bullying}

O bullying é a face mais visível dos problemas e discriminações enfrentados na escola pelas crianças e jovens diversos em termos de género. E, como a análise empreendida revelou, é um problema que atinge intensamente esta população, tanto mais quanto a sua expressão de género não normativa for notada (Whittle, Turner, e Al-Alami 2007; Cabrera e Cabezas 2013; FRA 2014). O Comissário dos Direitos Humanos do Conselho da Europa reconhece que o bullying que se abate sobre a maioria das crianças percebidas como LGBT afeta a aquisição de conhecimentos e impede o seu direito à educação sem discriminação, alertando para que combater a intimidação transfóbica requer uma atenção contínua e focada das escolas e das autoridades escolares (Conselho da Europa 2014).

Os efeitos ou consequências do bullying não se limitam ao imediato e podem afetar todo o percurso de vida destas pessoas, nomeadamente o capital escolar com que poderão contar. Como a análise evidenciou e os testemunhos seguintes ilustram, desencadeia percursos escolares atribulados (mudanças de escola constantes, por exemplo), a suspensão do percurso escolar e o abandono escolar precoce.

A pressão era tanta, na escola, que eu não conseguia ir para as aulas. Eu chegava a levar a minha mochila, e saía de casa e só vinha à hora, porque não conseguia ir à escola [...]. Eu era completamente maltratada! Ainda me lembro que os miúdos vinham ter comigo e diziam: «tu és gay, tu és isto, tu és aquilo». Eles chegaram a fazer esperas à porta da escola, vinham atrás de mim, tentavam-me bater. Desde me apontarem uma ponta e mola ao pescoço, desde me apontarem facas de cozinha ao pescoço, até que comecei completamente a ter pavor. Eu fiquei num beco sem saída. A minha opção foi sair da escola. Eu saí da escola com 15 anos. (Daniela, 25 anos)

Estive um ano parado, sem estudar, porque eu tinha que dar uma volta, eu tinha que parar um bocado, porque tinha toda gente a discriminar-me [...] Uma vez passa um casal de namorados [...] e o namorado puxa-me as calças para baixo, eu tinha 10 anitos. Aos 12 anos fui estudar para um colégio. E então eu entrei nas aulas e no segundo dia eu já tinha pessoal à porta da escola para me pedir o BI, para me tirar fotografias. (Ricardo, 18 anos)

Os insultos homofóbicos, de que se ressentem sobretudo as feminilidades trans, têm na base as questões de género no sentido em que a heterossexualidade é uma das componentes constitutivas sobretudo da masculinidade. A análise das experiências relatadas demonstra a recorrência de ser lido/a como gay, ou seja, da atribuição da «diferença» à orientação sexual. Isto revela quer a relação íntima que o modelo de género estabelece com a heterossexualidade, quer ainda o desconhecimento acerca do fenómeno e respetivos termos para o referenciar.

Assim, e tal como encontrado noutras realidades, a violência transfóbica ainda dificilmente é reconhecida como tal. É uma violência sobre a qual «quase 
ninguém fala, que permanece severamente invisibilizada» (Cabrera e Cabezas 2013 , 9). Mas é preciso encarar o bullying não enquanto casos particulares e isolados de transfobia, mas como uma manifestação institucional e sistemática do sexismo (Cabezas, Ortega e Galán 2013). Daí que, sendo necessárias medidas que atuem de imediato nesses casos, estas terão que ser acompanhadas de outras mais transversais e estruturais. Estando o sexismo e as normas de género na origem da discriminação, o combate ao bullying transfóbico, tal como ao homofóbico, insere-se plenamente no combate à violência de género. Isso mesmo é defendido pela Agência dos Direitos Fundamentais da União Europeia (FRA) no parecer que decorre do estudo Ser Trans na UE: «As escolas devem ser incentivadas a adotar medidas antibullying de caráter geral que incluam questões trans» e «A UE deve ajudar a combater o bullying das pessoas trans nas escolas [...] como parte dos seus esforços para combater os estereótipos de género através da Estratégia da UE para a igualdade entre mulheres e homens» (FRA 2014, 6).

\section{Tentativas de suicídio}

Expressar-se diversamente em termos de género não é uma patologia, mas o cisgenderismo da sociedade pode levar, e frequentemente leva, a problemas de saúde mental, de consequências dramáticas. As tentativas de suicídio, já identificadas na literatura como de elevada incidência nesta população (Peterson et al. 2016), foram também encontradas entre as pessoas trans entrevistadas (três casos).

Aos 14 fiz uma tentativa de suicídio porque pensava que não havia solução, e então preferia morrer... depois andei em psiquiatras... Eles afirmavam que eu era homossexual, os próprios psiquiatras não sabiam o que era a transexualidade [...] até que fui à psicóloga da escola, fui tentar, a ver o que é que dava. Comecei a ir, ela notava que havia uma coisa diferente em mim, não sabia o quê porque eu também não falava... Eu não expressava porque eu tinha receio que acontecesse o mesmo que aconteceu com os psiquiatras, a eles tinha-lhes dito, e como eles não tinham ligado... Estive lá ano e meio, e depois ela encaminhou-me. Ela informou-se. Ela sabia do que se tratava. [...] ajudou-me bastante nessa fase, na fase do $10{ }^{\circ}, 12 .^{\circ}$, esteve presente muitas vezes. (Miguel, 26 anos)

O testemunho de Miguel é bem revelador da importância das escolas estarem dotadas de profissionais na área da psicologia com formação nestas questões. Mas, mostra ainda, e a montante, a necessidade de disponibilização de informação sobre identidades de género, já que, na sua ausência, estas crianças e jovens não conseguem referentes identitários para a sua legibilidade enquanto pessoa. Tal informação não deverá estar acessível apenas a crianças e jovens que aparentam dela precisar mas a todas as crianças e jovens, nem que seja pela frequente não partilha deste sentimento. 


\section{A violência do não reconhecimento}

Mesmo quando não há indícios óbvios de discriminação ou de mal-estar, nem que seja porque as crianças e jovens utilizam a sua agência e desenvolvem estratégias de vivência ou até de sobrevivência no espaço escolar, a violência está presente na interdição da autenticidade: «disfarçar», «não poder ser quem se é» ou «invisibilizar-se» (Gavilán 2016, 133) (também) na escola. No sentido oposto ao utilizado por Garfinkel (1967), as crianças e jovens trans relatam estratégias no sentido de «passar» por crianças conformes em termos de género.

Uma estratégia de evitamento da discriminação é a autovigilância, a contenção, a não partilha. E, na escola, a autovigilância exerce-se de muitas maneiras, mesmo nas menos óbvias.

Há pouco tempo estive a ver aquelas pastinhas que nós temos quando estamos na escola primária, onde pomos os desenhos, e eu desenhava muitas flores, muitas borboletas, mas pronto, lá está, tinha que ser assim de uma forma muito dissimulada. Desde muito pequenina que aprendi que certas coisas tinham que ser só comigo própria, sozinha é que poderia exprimir certas coisas, com outras pessoas não era possível, porque não iriam compreender. (Patrícia, 22 anos)

A esmagadora maioria das pessoas trans não conhece, na infância, ninguém com uma identidade ou expressão de género semelhante à sua, ou nem sequer sabe que existem, o que leva a experienciar esse sentimento, de acordo com o que é recebido do seu entorno, como «anormal». Tal como apurado noutras realidades (Kennedy 2010), nenhuma das pessoas auscultadas tomou conhecimento das questões da identidade de género e de transgénero na escola.

Para já, eu achava que era a única criança-adolescente, pré-adolescente do mundo a sentir aquilo e... Não tinha conhecimento de nenhum outro caso, não encontrava ninguém parecido, ao mesmo tempo não tinha coragem de falar sobre isso exatamente porque era o único. [...] portanto, guardava, fui guardando para mim. (José, 28 anos)

O direito à identidade e expressão de género passa pois pelo direito à informação - sobre o que se é e os direitos que se têm. A recente visibilização de crianças e jovens trans é também possibilitada pela informação que vai estando mais acessível, se não na escola em outros meios (comunicação social, Internet). Mas a escola é o meio que oferece mais garantias, em termos de abrangência, qualidade dos conteúdos transmitidos e adequação à idade, tal como assumido pelo Comissário dos Direitos Humanos do Conselho da Europa (Conselho da Europa 2014).

Reforça-se assim a evidência da necessidade de revisão do conteúdo dos manuais escolares, já identificada para o combate às desigualdades de género (Alvarez e Vieira 2014; Cardona 2015), para que incorpore simultaneamente as 
questões transgénero, por exemplo, não reproduzindo a associação automática entre corpos e identidades de género.

Diversos estudos têm evidenciado a importância de contar a sua história e de ouvir a de «outros semelhantes» como parte do processo de compreensão da identidade trans (p. ex., McNamara e Rooke 2006). A abertura colaborativa da escola a entidades da sociedade civil, nomeadamente associações LGBT, é um caminho possível e desejável, podendo ser potenciados instrumentos e práticas de que estas já dispõem, como materiais pedagógicos e sessões de formação entre pares. ${ }^{11}$

No caso de crianças e jovens com uma identidade trans acresce ainda a violência do não reconhecimento do direito fundamental à identidade de género. $\mathrm{A}$ utilização de um nome e de um género gramatical com que não se identificam é sentida como uma negação da sua existência.

Eu sentia que as pessoas não me conheciam, porque estarem a tratar-me no feminino é como se não estivessem a falar para mim. [...] É difícil ter amigos com uma máscara, não é? (André, 32 anos)

Revelam-se assim necessários procedimentos que possibilitem e assegurem que as escolas respeitam a identidade de género - nome e género gramatical de todas as pessoas que as frequentam, no tratamento e nos documentos formais (cadernetas, pautas, etc.), independentemente do sexo de registo.

\section{O (trans)género na escola. Desafios para o futuro}

A análise das experiências escolares de pessoas trans em Portugal, que deverá ser continuada e complementada com estudos que tomem o fenómeno como principal foco analítico, evidenciou, à semelhança do encontrado em outros contextos, o isolamento, discriminação e assédio escolar a que estão sujeitas as crianças e jovens que põem em questão o binarismo de sexo/género (Meyer 2009; Cabezas, Ortega e Galán 2013; Gavilán 2016). Os testemunhos recolhidos numa época pré-aquisição de direitos para a diversidade de género compõem um panorama de desamparo e falta de apoio institucional que urge ultrapassar. $\mathrm{O}$ momento atual é decisivo, havendo compromissos políticos para a igualdade e a diversidade de género, nomeadamente com o novo programa de Educação para a Cidadania, que tomam a escola como campo de atuação e, expectavelmente, de transformação.

Ao longo do artigo, deixaram-se pistas de medidas específicas necessárias à atenção à diversidade de género no sistema de ensino, algumas das quais já implementadas noutros contextos, e que podem servir de referente de boas práticas. Por exemplo, a disponibilização de procedimentos que possibilitam que as crianças e

11 Por exemplo, o «Projeto educação LGBT» da rede ex aequo e os projetos «Tod@s Som@s Precis@S» e «Aliança da Diversidade» da ILGA Portugal. 
jovens se apresentem e sejam reconhecidas com o nome e género gramatical com que se identificam, quer no trato pessoal, quer nos documentos administrativos, ou o livre acesso a espaços (como balneários e casas de banho) e atividades (como as desportivas), independentemente do sexo de registo.

Para além de medidas mais específicas, tentou demonstrar-se também a pertinência, justeza e adequação de incluir as questões da diversidade de género e de transgénero nas políticas de promoção da igualdade de género no sistema educativo. Se as políticas de promoção da igualdade e cidadania de género assentam na erradicação do sexismo, definido como «conceito que abrange todos os preconceitos e formas de discriminação exercidas contra um indivíduo devido ao respetivo sexo» (Cardona 2015, 9), o combate ao cisgenderismo cabe aqui inteiramente, como o demonstraram as experiências das pessoas trans na escola. E se uma das lacunas detetadas no sistema de ensino para o cumprimento das suas potencialidades no trabalho em prol da igualdade de género é a insuficiente integração da investigação produzida sobre género na educação (Comissão Europeia 2012), no âmbito dos Estudos sobre as Mulheres e dos Estudos de Género (Alvarez e Vieira 2014, 14), a estes deverão juntar-se os estudos sobre Transgénero e Diversidade de Género.

A promoção da igualdade de género deverá incluir a diversidade de género, que a beneficia e a enriquece. A educação sexual ainda hoje começa com uma compreensão binária do sexo e do género - dois tipos de corpos diferentes que se desenvolvem em dois tipos distintos de trajetórias previsíveis (Pyne 2014, 5). A introdução de outras possibilidades, como as vivenciadas pelas crianças trans e diversas em termos de género, vem contribuir para perturbar a rigidez e flexibilizar as normas de género. Para todas as crianças e jovens e não apenas para aquelas que poderão recair na alçada do transgénero.

\section{Referências bibliográficas}

Alvarez, Teresa, e Cristina C. Vieira. 2014. «O papel da educação no caminho que falta percorrer em Portugal na desconstrução dos estereótipos de género: breves reflexões». Exedra: 8-17. Disponível em http://www.exedrajournal.com/wp-content/uploads/ 2014/12/sup14-8-17.pdf

Ansara, Y. Gavriel, e Peter Hegarty. 2012. «Cisgenderism in psychology: Pathologizing and misgendering children from 1999 to 2008». Psychology E Sexuality 3 (2): 137-160. DOI: https://doi.org/10.1080/19419899.2011.576696

Bryant, Karl. 2006. «Making Gender Identity Disorder of Childhood: Historical Lessons for Contemporary Debates.» Sexuality Research and Social Policy 3 (3): 23-39. DOI: https:// doi.org/10.1525/srsp.2006.3.3.23

Butler, Judith. 2004. Undoing Gender. New York/London: Routledge.

Cabezas, Luis P., Elena M. Ortega, e José I. P. Galán. 2013. «Adolescentes transexuales en la escuela. Aproximación cualitativa y propuestas de intervención desde la perspectiva antropológica». In Transexualidad, Adolescencias y Educación. Miradas multidisciplinares, 
editado por Octavio M. Cabrera e Luis P. Cabezas, 97-131. Barcelona/Madrid: Egales Editorial.

Cabrera, Octavio M., e Luis P. Cabezas. 2013. «Introducción». In Transexualidad, Adolescencias y Educación. Miradas multidisciplinares, editado por Octavio M. Cabrera e Luis P. Cabezas, 7-13. Barcelona/Madrid: Egales Editorial.

Cardona, Maria José (coord.), Conceição Nogueira, Cristina Vieira, Marta Uva, e Teresa-Cláudia Tavares. 2015. Guião de Educação Género e Cidadania. Pré-Escolar. Lisboa: Comissão para a Cidadania e Igualdade de Género (CIG). Disponível em https://www.cig. gov.pt/wp-content/uploads/2015/10/398_15_Guiao_Pre_escolar.pdf

Comissão Europeia. 2012. Exchange of good practices on gender equality. Gender Training in Education. Summary report. Disponível em http://ec.europa.eu/justice/gender-equality/files/tools/summary_report_pt2012_en.pdf

Comissão Europeia. 2015. Eurobarometer on discrimination 2015. General perceptions, opinions on policy measures and awareness of rights. Factsheet. Disponível em http:// ec.europa.eu/justice/fundamental-rights/files/factsheet_eurobarometer_fundamental_rights_2015.pdf

Conselho da Europa. 2010. CM/Rec(2010)5PT Recomendação do Comité de Ministros aos Estados-Membros sobre medidas para o combate à discriminação em razão da orientação sexual ou da identidade de género. Disponível em https://wcd.coe.int/ViewDoc. jsp? $\mathrm{p}=\& \operatorname{Ref}=\mathrm{CM} / \operatorname{Rec}(2010) 5 \&$ Language $=$ lanPortuguese

Conselho da Europa. 2014. The Commissioner's Human Rights Comments - Human Rights comment: LGBTI children have the right to safety and equality, 02/10. Disponível em https://www.coe.int/en/web/commissioner/-/lgbti-children-have-the-right-to-safetyand-equality

Costa, Carlos Gonçalves, Miguel Pereira, João Manuel de Oliveira, e Conceição Nogueira. 2010. «Imagens Sociais das pessoas LGBT». In Estudo sobre a Discriminação em Função da Orientação Sexual e da Identidade de Género, organizado por Conceição Nogueira e João Manuel de Oliveira, 93-148. Lisboa: CIG. Disponível em http://cid.cig.gov.pt/nyron/ Library/catalog/winlibimg.aspx?skey=8E0768F7645A4957A87149C2A421405B\&doC $=9021$ \&img $=139715$

Devor, Holly. 1989. Gender Blending. Confronting the Limits of Duality. Bloomington, IN: Indiana University Press.

Ehrensaft, Diane. 2012. «From gender identity disorder to gender identity creativity: True self child therapy». Journal of Homosexuality 59 (3): 337-356. DOI: https://doi.org/10.10 80/00918369.2012.653303

Ekins, Richard, e Dave King. 2006. The Transgender Phenomenon. London: Sage.

Enke, Anne (Finn). 2012. «The education of little cis: cisgender and the discipline of opposite bodies». In Transfeminist Perspectives in and behind Transgender and Gender Studies, editado por Anne (Finn) Enke, 60-80. Philadelphia: Temple University Press.

FRA - Agência dos Direitos Fundamentais da União Europeia. 2014. Ser Trans na UE: Análise comparativa dos dados do inquérito LGBT europeu. Viena: FRA. Disponível em http://fra. europa.eu/en/publication/2014/being-trans-eu-comparative-analysis-eu-lgbt-surveydata

Gavilán, Juan. 2016. Infancia y transexualidad. Madrid: Catarata.

Garfinkel, Harold. 1967. Studies in Ethnomethodology. Englewood Cliffs, NJ: Prentice-Hall. Disponível em https://archive.org/details/HaroldGarfinkelStudiesInEthnomethodology

Junta de Andalucia. 2015. «Protocolo de Actuación sobre Identidade de Género en el Sistema Educativo Andaluz». Disponível em http://www.juntadeandalucia.es/educacion/webportal/ishare-servlet/content/0c4f4c50-b038-48c0-9a80-de10bf5ad75a 
Kennedy, Natacha. 2010. «Transgender children: more than a theoretical challenge». Graduate Journal of Social Sciences 7 (2): 25-43. Disponível em http://gjss.org/issues/07/02

Lev, Arlene I. 2004. Transgender Emergence: Therapeutic guidelines for working with gendervariant people and their families. New York: The Haworth Clinical Practice Press.

Maroy, Christian. 1997. «A análise qualitativa das entrevistas». In Práticas e Métodos de Investigação em Ciências Sociais, editado por Luc Albarello et al., 117-155. Lisboa: Gradiva.

McNamara, Catherine, e Alison Rooke. 2006. Creative Encounters. London: Wellcome Trust.

Meadow, Tey. 2011. «'Deep down where the music plays': How parents account for childhood gender variance». Sexualities 14 (6): 725-747. DOI: https://doi.org/ $10.1177 / 1363460711420463$

Menvielle, Eduardo. 2012. "A comprehensive program for children with gender variant behaviors and gender identity disorders». Journal of Homosexuality 59 (3): 357-368. DOI: https://doi.org/10.1080/00918369.2012.653305

Meyer, Elizabeth. J. 2009. Gender, bullying and harassment: Strategies to end sexism and homophobia in schools. New York: Teachers College Express.

Ministry for Education and Employment. 2015. Trans, Gender Variant and Intersex Students in Schools Policy. Malta. Disponível em https:/education.gov.mt/en/resources/ Documents/Policy\%20Documents/Trans, \%20Gender\%20Variant $\% 20$ and $\%$ 20Intersex $\% 20$ Students $\% 20$ in $\%$ 20Schools\%20Policy.pdf

Monro, Surya. 2010. «Towards a sociology of gender diversity». In Transgender Identities. Towards a Social Analysis of Gender Diversity, editado por Sally Hines e Tam Sanger, 242-258. New York: Routledge.

Olson, Kristina R., Lily Durwood, Madeleine DeMeules, e Katie A. McLaughlin. 2016. «Mental health of transgender children who are supported in their identities». Pediatrics 137 (3): e20153223. Doi: https://doi.org/10.1542/peds.2015-3223

Peterson, Claire, Abigail Matthews, Emily Copps-Smith, e Lee Ann Conard. 2016. «Suicidality, Self-Harm, and Body Dissatisfaction in Transgender Adolescents and Emerging Adults with Gender Dysphoria». Suicide and Life-Threatening Behavior 47 (4): 475-482. DOI: https://doi.org/10.1111/sltb.12289

Pichardo, José Ignacio (ed.). 2009. Adolescentes ante la diversidad sexual. Madrid: Catarata.

Pinto, Nuno. 2015. Experiencing and representing transsexuality: developmental trajectories of, and social representations on, transsexual people. Tese de Doutoramento em Psicologia. Lisboa: ISCTE-IUL.

Platero, Raquel (Lucas). 2010. «Estrategias de afrontamiento frente al acoso escolar: Una mirada sobre las chicas masculinas». LES Online 2 (2): 35-51. Disponível em https:// lesonlinesite.files.wordpress.com/2017/03/estrategias-de-afrontamiento.pdf

Platero, Raquel (Lucas). 2014. «The influence of psychiatric and legal discourses on parents of gender non-conforming children and youths in Spain». Journal of GLBT Family Studies 10 (1-2): 145-167. DOI: https://doi.org/10.1080/1550428X.2014.857232

Pyne, Jake. 2014. «Gender independent kids: A paradigm shift in approaches to gender nonconforming children». Canadian Journal of Human Sexuality 23 (1):1-8. DOI: https://doi. org/10.3138/cjhs.23.1.CO1

Rahilly, Elizabeth P. 2015. «The gender binary meets the gender-variant child: Parents' negotiations with childhood gender variance». Gender E Society 29 (3): 338-361. DOI: https://doi.org/10.1177/0891243214563069

Riley, Elizabeth A. et al. 2013. «Recognising the needs of gender-variant children and their parents». Sex Education 13 (6): 644-659. DOI: https://doi.org/10.1080/14681811.2013.79 6287 
Rodrigues, Liliana. 2016. Viagens Trans(Género) em Portugal e no Brasil: Uma Aproximação Psicológica Feminista Crítica. Tese de Doutoramento em Psicologia. Faculdade de Psicologia e de Ciências da Educação da Universidade do Porto.

Saleiro, Sandra Palma. 2013. Trans Géneros: Uma abordagem sociológica da diversidade de género. Tese de Doutoramento em Sociologia. Lisboa: ISCTE-IUL.

Sanger, Tam. 2010. «Beyond gender and sexuality binaries in sociological theory: the case of transgender inclusion». In Transgender Identities. Towards a Social Analysis of Gender Diversity, editado por Sally Hines e Tam Sanger, 259-276. New York: Routledge.

Stryker, Susan. 2008. Transgender History. Berkeley, CA: Seal Press.

Yogyakarta Principles. 2007. The Yogyakarta Principles. Principles on the Application of International Human Rights Law in Relation to Sexual Orientation and Gender Identity. International Commission of Jurists. Disponível em http://www.yogyakartaprinciples.org/wp/ wp-content/uploads/2016/08/principles_en.pdf

Whittle, Stephen, Lewis Turner, e Maryam Al-Alami. 2007. Engendered Penalties: Transgender and Transsexual Peoples' Experiences of Inequality and Discrimination. Manchester: Press for Change/Manchester Metropolitan University.

Sandra Palma Saleiro. Doutorada em Sociologia pelo ISCTE-IUL, investigadora do Centro de Investigação e Estudos de Sociologia (CIES) do Instituto Universitário de Lisboa (ISCTE-IUL). Encontra-se a desenvolver o projeto «Diversidade de género, cidadania e saúde» no âmbito da FCT - Fundação para a Ciência e a Tecnologia. Endereço eletrónico: sandra.saleiro@iscte.pt

Artigo recebido a 31 de maio de 2017 e aceite para publicação a 2 de novembro de 2017. 
